\title{
Merging dualities: How convergence points in art and science can (re)engage women with the STEM field
}

\author{
Bettina Elisabeth Eva Forget, Concordia University \\ bettinaforget@gmail.com
}

\begin{abstract}
How can the interweaving of knowledge silos help to engage girls who are becoming disinterested in science? This study describes how convergence points in research practices within the fields of art and science can mitigate gender stereotypes associated with the STEM field. A case study of four women working at the intersection of art and science revealed common aspects of their practices: an appreciation of the natural world, a sense of aesthetics, a drawing practice and a reliance on meaningful research questions, suggesting that these can act as bridges between both fields of study.
\end{abstract}

Keywords: Arts; Education; Art-science; STEM; STEAM; Leaky pipeline; Gender; Motivation; Stereotype threat; Self-efficacy; Transdisciplinarity; Nature; Drawing; Aesthetics.

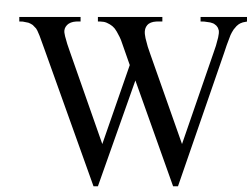
omen are underrepresented in the Science, Technology, Engineering, and Math (STEM) workforce, a situation that is often referred to as the leaky pipeline (National Research Council, 1991). The metaphor describes the attrition of girls and women in the STEM field from the time they enter elementary school until they choose careers in the job market. Throughout elementary school, girls and boys tend to engage equally in all academic subjects, but this picture changes as they enter adolescence (Leaper \& Spears Brown, 2008; Vincent-Ruiz \& Schunn, 2017; Wolfe, 2019). Teenage girls begin to self-select out of STEM subjects, and this trend continues throughout high school and college (NSERC, 2017).

However, reports have shown that girls and boys perform equally well in standardized science tests at various grade levels (NSERC, 2017; PISA, 2015). Studies suggest that that the gender gap is rooted in the way the field of science is perceived by girls (Blickenstaff, 2005; Tan et al., 2013; Vincent-Ruz \& Schunn, 2018) and that girls underestimate their abilities in science (Cheryan et al., 2017; Wolfe, 2019). The reasons for this self-censorship are wide-ranging and include societal pressures as well as pedagogical approaches. Since students tend to select academic subjects in which they feel they may excel and better match their self-concept, girls tend to gravitate toward other subjects, particularly the humanities and the arts (Kessels, 2014; Steele \& Ambady, 2006). Studies into girls' preferred learning styles (Jacobs et al, 2014; Kuriloff et al, 2017) suggests that girls particularly enjoy class activities that are hands-on and include creativity and the creative arts. Therefore, integrating arts into STEM teaching may provide access points for girls to (re)engage with the STEM field.

This approach may be of special interest to educational researchers working in the field of STEAM education. STEAM education interweaves art with STEM subjects with the aim of advancing innovative practices. Could girls' interest in the arts be used as a strategy to reconnect girls with STEM? To investigate this question, I conducted a case study that examined two institutions where art and science intersect: the Exploratorium in San Francisco - a museum of science, art, and human perception, and the SETI (Search for Extraterrestrial Intelligence) Institute 
- an organization that is dedicated to the search for extraterrestrial life. Using comparative case study design, this research explored both institutions' philosophies and institutional practices by conducting interviews and documenting the work environment using photo and video recordings. I also reviewed literature by and about each institution pertaining to their mandate and company history to ascertain an understanding of the organization's vision and work culture. The main focus of this study are four women who were interviewed about their experiences working in the field of science, and how they integrate art into their work and personal lives. The study highlighted their motivation for choosing careers in science and science-informed art and revealed convergence points where these research practices intersect.

\section{An Introduction of the Sites and Participants of this Study}

This study examined two institutions which engage in science research, outreach, and education: the Exploratorium, an interactive science museum located in San Francisco, California, and the Search for Extraterrestrial Intelligence Institute (SETI), located in Mountain View, California. The Exploratorium was one of the first museums to structure itself around interactive hands-on exhibits and identifies itself as "a public learning laboratory exploring the world through science, art, and human perception" (About Us, n.d., para. 1). Frank Oppenheimer, the Exploratorium's founder, called it "a museum of concepts" (Cole, 2009, p. 166) which emphasizes the act of discovery, play, and lifelong learning.

The SETI Institute is a non-profit organization which is dedicated to "addressing questions concerning the existence, evolution, and prevalence of life in the universe" (Carl Sagan Center, n.d., para. 1) The Institute engages in groundbreaking scientific research in the areas of radio astronomy, signal processing, exoplanet research, and astrobiology. In 2010 the SETI Institute launched its Artist-in-Residence (AIR) program which connects artists with SETI scientists as part of the SETI Institute's outreach program. The AIR program's aim is to catalyze new perspectives and insights that enrich both the scientists' and the artists' research, and to introduce the work that takes place at the SETI Institute to a wider audience (SETI AIR, n.d.).

At both the SETI Institute and the Exploratorium, I interviewed staff scientists, artists, exhibition designers, educators, curators, and managers to create a picture of the organizations' core philosophies, mandate, and organizational structure. While I conducted a total of 16 interviews with both men and women during the data collection process, I selected the stories of Jill Tarter, Margaret Race, Susan Schwartzenberg, and Nicole Catrett for this study, who offered especially detailed and comprehensive accounts of their life and work in the fields or art and science. The women's narratives provided compelling insights into their motivations for entering the field of science or science-informed art and highlighted several areas where their research practices converged. All four women are high-profile leaders in their fields, actively engaged in public outreach, and each woman chose to be identified in this study.

Jill Tarter is the former Chair Emeritus of the SETI Institute's Center for SETI Research. She currently holds the Bernard M. Oliver Chair for SETI and serves on the board of the Allen Telescope Array. Jill earned her Ph.D. in radio astronomy at Berkeley University and was one of the first employees of the fledgling SETI Institute when it was still part of NASA. She has dedicated her entire career to the search for extraterrestrial life (Scoles, 2017), and was the inspiration for Carl Sagan's (1985) book Contact. Margaret Race is an ecologist and planetary protection scientist. She joined the SETI Institute in 1991 to explore possible cross-contamination issues between Earth and other planets that may result from space missions. Margaret's recent work focuses on NASA projects related to Mars exploration, as well as shaping planetary 
protection policy regarding missions to solar system planets (Jacobs, 2011; Race, 1995; Personal Communication, July 22, 2016). Susan Schwartzenberg is the Director and Curator of the Exploratorium's Fisher Bay Observatory, an exhibition space and research centre which is located on the museum's top floor. Susan is a trained artist whose work centers on environmental issues and sustainability. She was a Loeb Fellow for Advanced Environmental Studies at the Harvard Graduate School of Design, and she has worked on several public art projects (Susan Schwartzenberg, n.d.; Personal Communication, August 9, 2016). Nicole Catrett is an artist and exhibit developer working in the Exploratorium's Learning Studio, a research-and-development group whose mandate focuses on hands-on teaching and exhibit development. At the Exploratorium, Nicole collaborates with international artists and educators, and she also maintains an independent artistic practice (Nicole Catrett, n.d.; Personal Communication, June 1, 2016).

\section{Method}

This research employed case study methodology, an empirical in-depth investigation that examines phenomena as they unfold in their real-life contexts (Yin, 2009). Case study design can be used to build a tentative hypothesis, and thereby plays an important role in advancing a field's knowledge base (Merriam, 2002). This research is an interpretive case study, which includes elements of categorization, contains thick descriptions, and is used to typify, bolster, and test theoretical assumptions (Merriam, 2002). In this study, these theoretical assumptions relate to the issue of the interweaving of the disciplines of art and science and how this may mitigate genderspecific hurdles for entering the STEM field.

I conducted semi-structured interviews with the women at their place of work and collected additional data by making photo and video recordings of their work environments. The semi-structured interviews explored the women's educational background, their interest in art and science, any gender-related obstacles they may have encountered, and their current area of research. Interview topics also included the mandate of the institution where they work, and its link to art, science, and education. While the accounts of the four women who form the basis of this case study are personal and unique, each story connected to larger insights about underlying motivations to choose a career in science or science-informed art, and revealed connection points between the arts and the STEM field.

During the process of analysis, I paid close attention to the women's particular modes of expression and personal narrative by using In Vivo coding, which captures the interviewees' words or short phrases in verbatim (Saldaña, 2009). During the second coding cycle, I employed Axial Coding, which defines the properties and dimensions of categories and connects them to relevant sub-categories (Charmaz, 2006). The themes and categories which emerged during the first cycle of coding were organized into a visual map using the mind mapping software called Freemind (Müller et al., 2014). Saldaña (2009) encourages the use of illustrative techniques, such as flow diagrams, as this practice can enliven abstract codes and analytic memos, and can suggest connections and narratives that may otherwise be overlooked. The developing structure of the map revealed a primary narrative that was then connected to the theoretical framework.

\section{Literature Review}

Gender stereotypes in the STEM field

The discussion surrounding the underrepresentation of women in the STEM field has been ongoing for several decades. In the 1990s, the metaphor of the leaky pipeline gained hold in educational theory, describing the attrition of women as they progress through the educational 
system in the fields of science, technology, and engineering (Matyas \& Dix, 1992; National Research Council, 1991; Pell, 1996). While progress has been made regarding the percentage of women participating in the STEM field, the gender gap persists. A 2017 NSERC study found that while university enrollment by women in Canada from 2005-2014 had increased overall, the proportion of women in STEM fields had remained largely unchanged at an average of $34 \%$. The study ascertained that in Canada the probability of a girl enrolled in grade one in Canada going on to receive a Ph.D. in the sciences or engineering was approximately 1 in 225 , compared to 1 in 117 for boys. A recent longitudinal analysis by Statistics Canada (Frank, 2019) found that Canadian women are less likely to enter the STEM field after graduation than men and are more likely to transition to a non-STEM occupation within ten years.

The reasons for the attrition of girls and women in the STEM field are complex. An issue frequently addressed are possible differences in the aptitude between girls and boys in math and science. However, longitudinal studies such as those by the 2015 OECD Programme for International Student Assessment (PISA) and NSERC (2017) found that the difference in science achievement scores between girls and boys were minimal. When Canadian boys and girls were assessed at various grade levels, the NSERC study found that they performed equally well and that any statistical differences tended to be small. Research reports such as those by Blickenstaff (2005), Brotman and Moore, (2007), Holmes et al., (2016), and Wang and Degol (2016) have examined a multitude of factors including girls' attitudes toward science, a lack of female role models, the pedagogical style of science education, gender bias in scientific epistemology, and unwelcoming work climates in the STEM field.

What emerged from these reports is that a significant factor contributing to the underrepresentation of women in STEM is gender stereotypes. Gender-role pressures increase in adolescence, especially for girls. A study by Leaper and Spears Brown (2008) details that adolescent girls between 12 and 18 years of age experience a period of gender intensification where they become increasingly sensitive to gender-role pressure, including notions regarding women's efficacy in science. The authors found that the majority of girls in their study had heard derogatory remarks about their STEM skills at least once, and that the view that girls do not belong in the sciences was prevalent among both girls and boys. These stereotypes impact girls' science identity, defined by Vincent-Ruiz \& Schunn (2018) as a composition of self-views pertaining to a sense of belonging to the science community. The authors found that students' science identity in grades seven and nine was lower for girls than for boys, which negatively impacted girls' participation in STEM subjects. The entanglement of feminine stereotypes and girls' science identity was also addressed by Francis et al., (2017) in a study of 15-year-old students, which revealed that the gender construct of the "girly girl," a term which denotes highly stereotypical feminine behaviours, was deemed incompatible with the pursuit of science and mathematics.

Teenage girls' low science identity connects to their competency beliefs in the STEM field. Vincent-Ruiz and Schunn's (2017) study of sixth and eighth grade girls showed that as girls grow older, their competency beliefs strongly affect their science achievement. The masculine culture associated with the STEM field, where scientists and scientific objectivity are perceived as male, causes "stereotype threat" in girls, an underlying fear that they are not "natural" scientists and do not belong in the STEM field. For example, Wolfe (2019) found that high school girls nominated mathematics as the most disliked and problematic subject, and self-reported high anxiety levels over mathematics. Wolfe found that the girls saw themselves as not "good enough" to do math and did not want to risk underperforming in a high-status subject. Ideas regarding low self-efficacy and self-views persist, and even increase in college and university (Cheryan et al., 2017). On the 
flip side of this gender and identity stereotyping is girls' perception that they are competent in languages and the arts, domains which are typically associated with femininity (Lupart et al, 2010; Meece et al., 2006; Steele \& Ambady, 2006). Since students tend to select academic subjects in which they feel they may excel and better match their self-concept, girls tend to gravitate toward the humanities and the arts (Kessels et al., 2014, Kessels, 2014). Girls' interest in the arts may make STEAM education a pertinent strategy to (re)engage girls with the STEM field.

\section{STEAM and Transdisciplinarity}

Adding art to STEM is an idea that was advanced in 2008 by John Maeda, then president of the Rhode Island School of Design (RISD). Maeda coined the term STEAM (STEM plus Arts) with the aim to foster flexible thinking, risk-taking and creative problem solving (Maeda \& Joichi, 2015). Gettings (2016) describes the integration of the arts into STEM curricula as a "de-siloizing" (p. 10) and notes that the converging of subject areas leads to deeper, more contextualized learning. In the last decade, STEAM has become a growing trend in both science and art education, supporting various rationales and approaches ranging from fostering inquiry-based learning (Madden et al, 2013) to training "21st century skills" (Land, 2013, p. 549) such as programming and 3D modelling (Land, 2013; Wynn \& Harris, 2013).

The advantages of de-siloed STEAM curricula may help to mitigate stereotype threat by creating access to an academic field from which girls feel excluded. Kuriloff and colleagues (2017) found that the STEAM framework is especially beneficial for girls. Combining art and creative components with STEM subjects creates an access point that helps girls to transition from familiar ground to a field where they may experience anxiety. Peppler and Wohlwend (2017) examined how of STEAM education may invite participation from communities that are underrepresented in the STEM field, particularly girls. The authors see STEAM as a disruptive educational strategy with the potential to recalibrate gender norms. Peppler and Wohlwend's curricula drew on materials, tools, and practices stereotypically associated with girls such as fabric and needlework, and combined them with those typically associated with males, such as coding and electronics. The authors describe successful projects with e-textiles and the Scratch visual programming language which lead to girls' increased understanding of computational thinking and electronic circuity construction. Peppler and Wohlwend concluded that the synergies offered by STEAM curricula can make the STEM field more accessible while at the same time making the arts more culturally relevant.

However, too often in STEAM curricula, the arts component is treated as an afterthought to STEM rather than an integral element. Gettings (2016) calls this superficial inclusion of arts into the STEAM curriculum "POS" or "Paint on Stuff" (p. 11). In this context, art is not a part of meaning-making, it does not stimulate reflection, and very little experimentation is involved. A study by Clapp and Jimenez (2016) revealed that in STEAM education, the implementation of technology and engineering topics ranked very high at $95 \%$ and $91.7 \%$ respectively, whereas engagement with the arts lagged behind at only $36.7 \%$. In projects where the arts were integrated, the majority amounted to what the authors termed "STEM-with-stickers" (p. 486), meaning that the arts were incorporated superficially in an ornamental or decorative fashion that lacked engagement with creativity, aesthetics, or visual literacy. The authors see this as a missed opportunity and advocate for a more intentional and balanced integration of the arts in STEAM education. In a review of ACD (arts, crafts, and design) and STEMM (STEM plus medicine) integration practices, Root-Bernstein and colleagues (2019a) also argue against the perfunctory 
addition of artistic components to STEM subjects and contend that emphasis should be placed on connecting the various subjects on the basis of skill, materials, principles, and processes.

Some educational scholars propose that the educational framework of arts integration is the optimal way to combine the arts with non-art disciplines. Marshall (2014) defines arts integration as a field with its own distinct epistemology and practices that mobilizes the benefits artistic thinking brings to teaching and learning. The author explains that the transdisciplinarity inherent in arts integration acknowledges the component disciplines while contextualizing them based on their commonalities, thereby balancing disciplinary integrity with a holistic vision. Arts integration thus creates an interstitial space where new practices and insights can emerge. Transdisciplinary practice creates a holistic curriculum that is framed around ideas and students ' interests, resulting in more meaningful and less fragmented learning experiences (Bautista et al., 2016). This makes arts integration an excellent epistemological framework for STEAM education, as it removes the hierarchies of knowledge production and affords each discipline equal importance.

\section{Discussion}

Based on the discussions with the study's participants and an exploration of the institutions where they work, this research identified commonalities in the attitudes, interests, and research practices of practitioners working in the fields of art and science. These convergence points act as the interstitial space described by Marshall (2014) that is central to transdisciplinary practice. Four convergence points emerged as the most significant areas where art and science overlap: critical inquiry and asking "big questions," the natural environment as a catalyst for community engagement, aesthetics and its balance with functionality, and drawing as a tool for observing and ideation. The insights offered through the examination of successful female adult practitioners in their respective fields can serve as a road map to structure transdisciplinary curricula that can engage a younger population of learners. The convergence points of art and science intersect with aspects of girls' preferred learning styles as described in studies by Kuriloff et al. (2017), and therefore offer potential for the increased engagement of girls in STEAM education, as well as a more meaningful integration of arts in STEAM curricula.

\section{Questioning and Transdisciplinarity}

The most apparent convergence point that emerged from this research_is the practice of developing questions. Focusing on cross-cutting "big ideas" and posing fundamental questions underpins transdisciplinary epistemology as it creates conceptual connections that bridge disciplinary fields (Marshall, 2014). In the context of this study, "posing questions" means identifying a research question that guides current and future projects, the praxis of critical inquiry, and pondering open-ended questions.

Identifying a research question that is meaningful and connects to a personal sense of identity can motivate an entire career. In her biography Making Contact (Scoles, 2017), Jill Tarter relates her excitement when she discovered the area of SETI research during her tenure at Berkley, and the existential question it tackles: "Are we alone?"

This is the first time in history when we don't just have to believe or not believe.

[...] Instead of just asking the priests and philosophers, we can try to find an answer. This is an old and important question, and I have the opportunity to change how we try to answer it. (p. 67) 
Jill felt that by pursuing this potentially paradigm-shifting research question she could profoundly impact people's lives (Scoles, 2017). She saw the act of defining her own research question as empowering; an expression of agency. Jill stated that "science is creative - you've got to figure out your own problems and how to solve them - I think there is a lot of authority in that" (Personal Communication, July 8, 2016). This is an important insight to consider in an educational context. STEAM education curricula are often structured around research questions that are proposed by the instructors, typically in the form of design challenges. However, when students are allowed to select their own themes and questions, their sense of initiative and autonomy increases, and they feel more motivated (Bautista et al, 2016). Therefore, allowing the learners to develop their own research questions would better engage students and create learning experiences that are more meaningful to them.

Jill associates the notion of self-determination and engaging in critical inquiry with both scientific research and artistic practice. She helped found the SETI Institute's Artist in Residence program because she felt that artists can bring a fresh perspective and aid the SETI scientists to see their own work from a different angle.

The artists can help us see the work that we do in a different light, ask questions

like "why don't you do this?" - that can actually make a difference, and shine a

light into corners that we normally don't illuminate and maybe give us some new

ideas (Personal Communication, July 8, 2016).

The development of new perspectives through critical inquiry is an integral part of transdisciplinary practice. By posing unconventional questions and fostering multiple viewpoints, research praxis is freed from disciplinary frames of reference and allows for new insights (Constantino, 2002). When seen through the lens of artistic thinking in the educational context of art integration, learners can better explore and analyze the multilayered complexities of non-artistic subject areas (Marshall, 2014). When applied to STEAM education, grounding curricula in crosscutting "big questions" that traverse disciplinary boundaries creates multimodal, relevant learning situations that intentionally and meaningfully integrate the arts into STEM, thus avoiding the "STEM-with-stickers" (p. 486) effect described by Clapp and Jimenez (2016).

At the Exploratorium's Observatory, inquiry-based transdisciplinary research is facilitated through collaboration with external partners. For example, the Observatory is engaged in longterm scientific studies with institutional partners such as the National Oceanic and Atmospheric Administration (NOAA). Additionally, Susan Schwartzenberg has set up an artist-in-residence program as well as a scholar-in-residence program which generates projects that fuse art, science, and environmental studies. The aim of these institutional collaborations is to foster the crossfertilization of ideas and research practices. Susan explained that the guiding question of this transdisciplinary research is "How do we know what we know?" (Personal Communication, August 9, 2016).

Susan feels that the exhibit "Bay Lexicon" by the Canadian artist and landscape architect Jane Wolff (Wolff, 2013 - ongoing), who was the Observatory's artist-in-residence at the time of our conversation, exemplifies the successful integration of artistic and scientific practice through critical inquiry. The exhibit "Bay Lexicon" consists of 48 flash cards with simple line-drawing illustrations and questions about San Francisco's geographic and conceptual boundary with the Bay, which is visible from the Observatory. For example, a drawing of a person on a boardwalk holding a fishing line is accompanied by the question, "How is fishing connected to mining?" A drawing of the coastline near the Islais Creek is titled "Where does Islais Creek begin?" and then offers the choices, "a. channel, b. drawbridge, c. viaduct, d. headwaters." The questions on the 
cards are designed to spark discussion. The cards do not provide any answers, and it could be argued that there is no correct answer to any of the questions. It is the conversation and reflection itself that is the purpose of each card. For Wolff, critical inquiry is a means in itself, and the art installation's focus is on process, not on outcomes.

Susan appreciates how Wolff's exhibit uses art as a means to encourage visitors to think about environmental science and explains that Wolff has "put her intelligence to use around scientific concepts, ecological concepts, but still in an artful way. It delivers the message a little bit differently" (Personal Communication, August 9, 2016). For Susan, this transdisciplinary research is a perfect example of how art and science converge: "It's almost like it's not quite art or science" (Personal Communication, August 9, 2016). The Bay Lexicon connects science, culture, society, ecology, and art through the act of questioning and asks visitors to ponder their relationship with their environment.

\section{Nature and Community}

A deep appreciation for the natural world was the most consistent convergence point of art and science identified by this study. Every study participant, both artists and scientists, discussed how explorations of the natural world in their youth served as a catalyst for their passion in their respective disciplines. These encounters ranged from fishing trips and scuba diving expeditions to a fascination with insects or plants. This deep engagement with the natural environment is echoed in the educational context by girls' interest in the subject of biology. Studies examining educational trends within the STEM field show that school age girls prefer the subject of biology (NSERC, 2017; NSF, 2019) This tendency continues into their university years; women earn most undergraduate and graduate degrees in biosciences and later choose careers associated with biology and medicine (NSF 2019; Vincent-Ruiz, 2017). Some authors posit that this preference for biology over other subjects like physics or computer science is connected to girls' anxiety over their math skills (Wang \& Degol, 2016; Wolfe, 2019). This study points toward an additional reason girls and women are drawn to the biological science: a connection to environmental protection and community engagement. Studies by Kuriloff and colleagues (2017) have shown that girls are especially motivated by projects where they feel that they can make a difference. Therefore, linking science with ecology and public outreach contextualizes science learning and applies it in ways that are meaningful to girls.

Margaret Race's career is an example of how an appreciation for nature connects to environmental activism. In my interview with her (Personal Communication, July 22, 2016) she recounted how her love for "everything to do with water" developed into a career in planetary protection policy. Her activities as a swimmer and scuba diver sparked an interest in marine biology. Margaret's early academic research was focused on the impact of invasive species on North American waterways. Later in her career she was brought onto a Mars sample-return mission project by NASA to ascertain the possible threat of introducing novel and previously unidentified microbes from Mars to Earth's environment. Informed by her work in environmental science, Margaret realized that the spacecraft could equally contaminate Mars' environment with Earth's microbes. This insight led to the development of planetary protection protocols that are now require spacecraft to be fully sterilized or burn up in a planet's atmosphere. Margaret's planetary protection research at the SETI Institute combines astrobiology (the study of life beyond Earth) and policy work with NASA and governmental stakeholders to protect not only our own planet, but every celestial body visited by space missions. Yet even today Margaret describes herself 
simply as an ecologist, although her perspective has shifted from an anthropocentric point of view to include the environments of other planets.

Margaret's planetary protection work demonstrates how research in environmental science can lead to a transglobal and encompassing mindset that frames nature as a planetary system. Margaret's research connects to the work by Anderson and Guyas (2012), who champion deep ecology, a framework which challenges the anthropocentric world view and places humans in a network of life where all organisms occupy an equal and intrinsic place in the natural world. This approach is based on a profound reimagining of our place in nature and our relationship with the environment. An integral part of this philosophy is the concept is of interbeing, a social and political stance that questions our assumptions about our place in the world. Anderson and Guyas explore the notions of deep ecology and interbeing through an artistic approach they term Earth Education, which is a socially engaged transdisciplinary pedagogy and epistemology. This community-oriented stance intersects with girls' interests in choosing careers that benefit society and their interest in making a positive impact on the world. Here both art and environmental science connect with activism and community, and create an excellent grounding for STEAM education that will engage girls' interest.

Susan Schwartzenberg's work as director and curator of the Exploratorium's Observatory is informed by a fusion of her artistic practice and her strong advocacy for environmental issues. Susan's own public artworks, many of them installed in urban parks, invite the public to ponder the link between the natural environment and the history of urban development. Many of her installations feature "musing stations" which prompt park visitors to contemplate local histories and surrounding flora and fauna. Similarly, the Observatory's exhibits invite observation and reflection. She feels that her personal artistic practice dovetails with the Exploratorium's mandate. "[At] the Exploratorium, all our exhibits are about nature in one way or the other, the fundamental principles of nature" (Personal Communication, August 9, 2016). When Susan was tasked with creating the curatorial mandate for the Observatory, she felt that she had a chance to address what she saw as a gap in the museum's programming when it came to environmental issues. Susan took the opportunity to implement an environmental outreach mandate that extends beyond the walls of the Exploratorium and connects to the community. Her aim is to create a research space that allows scientists, policy makers, and educators to interact with each while also engaging the general public through events and environmental outreach activities. Susan explains, "I see it [the Observatory] being as much about programs and workshops and activities as displays of exhibits" (Personal Communication, August 9, 2016).

Susan's work is a blueprint for how environmental research transcends art and science. Her research takes on a critical stance, investigates local environments, and involves the local community. This approach is echoed in place-based education and the principles of eco-art. Critical place-based education is an educational framework proposed by Graham (2007) which considers local cultural and natural environments. This approach foregrounds both the aesthetic qualities as well as the political dimensions of place, nature, landscape, and wilderness. Using critical inquiry, place-based education fuses art making and social critique with activism, blurring the boundaries between environmental art and ecological research.

\section{Aesthetics and Functionality}

During my interviews with both artists and scientists, the word "aesthetic" recurred frequently in our discussions and emerged as the third art-science convergence point. In the context of art education, there has been extensive discourse on the topic of aesthetics. Educational 
philosopher Maxine Greene's (1986) rationale for aesthetics in art education outlines how perception, sensation, and imagination help us to understand and relate to the world. Similarly, Olivia Gude (2008) connects aesthetics to individual and collective meaning-making, which she defines as "the ability to engage and entertain ideas and images" (p. 101). Kevin Tavin (2008), however, critiques the current discourse of aesthetics in art education. He cautions that art education's emphasis on aesthetics borders on obsession, imbuing the concept of aesthetics with the magical effects of a Lancanian "Object a" of desire (p. 268). Instead, argues Tavin (2007), art educators should engage with the world unburdened by the ideologically loaded discourse of aesthetics. While Tavin proposes to strike through aesthetics, Paul Duncum (2007) argues for its continued use. He foregrounds the socio-political context of aesthetics in art education, noting that "aestheticized imagery" (p. 48) sustains contemporary economies, identifies cultural representation, and mediates ideologies.

In the context of STEAM Education, scholars endorse the integration of aesthetics in teaching and learning. Root-Bernstein and colleagues (2019b) advocate for the inclusion of aesthetics in science curricula, proposing that aesthetic experiences result in transformative and enduring learning outcomes. This stance is supported by scholars such as May and Clapp (2017), who suggest that adding art and aesthetics to science education encourages deeper thinking, better understanding, and a more extensive exploration of scientific principles. However, Clapp and Jimenez' (2016) investigation of the role of aesthetics in Maker culture, an interdisciplinary creative practice closely associated with STEAM, identified a counter-trend where the functionality of an object is favoured at the expense of its aesthetic appeal. The authors propose that this anti-aesthetic is a hallmark of the Maker movement and therefore constitutes its own idiosyncratic visual culture. Gude (2008) proposes that anti-aesthetic strategies are a means to disrupt conventional social and aesthetic attitudes, which would indeed dovetail with the Maker culture's mindset which aims to innovate, repurpose, and democratize. Emphasizing the functionality of an object is also a form of transparency. For example, Frank Oppenheimer, the founder of the Exploratorium, explicitly forbade the use of glue in any of the museum's exhibits, because it hides how materials are connected. Instead, exhibit designers were encouraged to use visible means of fastening, such as screws or wires, to make apparent how materials are held together (Cole, 2009).

Yet, despite this drive to reveal the mechanics of an object, May and Clapp's study found that the highest proportion of Maker educators and practitioners insisted that objects should appeal to the senses to engage an observer's interest. In the context of STEAM Education and Maker culture, aesthetics do play a role. This was apparent in Nicole Catrett's approach to exhibit design. When Nicole develops an exhibit, she focuses first on the aesthetics of the prototype. I interviewed her as she was creating and testing small mechanisms that demonstrated various types of linkages. She was designing an educational workshop in connection with the Exploratorium's exhibition Strandbeest by artist Theo Jansen (Jansen, 2016), a series of kinetic sculptures whose skeletal structures move when animated by the wind. During our discussion, Nicole explained how she balances aesthetics and functionality:

I was trying to make something aesthetically, so this is the one I made, it has a sculptural aesthetic that I was going for, but it didn't work at all. [My colleague] Sebastian had some suggestions about how to change the weight, and move this and all of a sudden it acts differently (Personal Communication, June 1, 2016).

The starting point of Nicole's project was its aesthetic component; for her an exhibit needs to "work" on an aesthetic level as well as on a mechanical level. For Nicole, the aesthetic aspect 
of the prototype is a core function of the project. Even while working within the Exploratorium's framework of mechanical transparency, she nevertheless attends to the way her workshop design appeals to the senses to engage the museum's visitors and inform their understanding of the underlying science. Nicole's approach highlights the importance of striking a balance between the functionality-focused anti-aesthetics of STEAM and Maker projects and their sensory-driven, perceptual aesthetic components. To avoid the "STEM with stickers" syndrome mentioned earlier by Clapp and Jimenez (2016), an emphasis on aesthetics needs to be integral in a STEAM curriculum. Clapp and Jimenez went so far as to suggest that the A in STEAM may stand for aesthetics and propose that more research should be conducted to develop a greater understanding of the aesthetic aspects of STEAM Education.

Additionally, a focus on aesthetics would be pertinent in the effort to attract more girls to the STEM field. In their book about girl's learning styles, Kuriloff et al (2017) found that artistic components such as the use of colour, the introduction of musical elements, and sensory play with modelling clay deepens girls' engagement and understanding of scientific processes. This insight is echoed by the 2019 Relevance of Science Education (ROSE) Report (Søberg \& Schreiner, 2019), an international study that surveyed the affective dimension of how young learners relate to the STEM field. The study found that girls are especially attracted to science topics that involve aesthetic aspects, such as questions relating to the appearance of colours and patterns in the natural world and how musical instruments produce sounds. Art educators can thus play an important role in the development of STEAM curricula by assuring that aesthetics is purposefully and meaningfully integrated into transdisciplinary projects.

\section{Drawing and Observing}

The fourth art-science convergence point identified by this research is the practice of drawing. Associations with the word "drawing" are common in the context of the visual arts, yet drawing practice is also prevalent in the domain of the sciences, such as drawing at the microscope, morphological field notations made by geologists, and concept sketches made by mathematicians (Anderson, 2017). In contemporary art education, the practice of drawing has transitioned from the pursuit of creating a polished artifact to a more process-oriented mode of visual research. Fava (2020) interviewed art educators to investigate attitudes toward contemporary drawing practice. The educators lamented that traditional drawing skills of school leavers had been decreasing over the last twenty years. This perceived decline in drawing ability was ascribed to a shift toward digital tools and lens-based media, as well as a more expanding definition of "drawing" that may include collage, photography, and referencing secondary sources. Today, drawing is valued as visual research used in process-driven ideation and problem solving, and for experimentation with visual expression (Owen, 2020). Yet Anderson and Guyas (2012) see value in a more traditional practice that encourages drawing from nature. The authors highlight that drawing is a potent strategy to help slow students down and foster a deeper engagement with nature through careful observation. In this context, drawing connects to the art-science convergence point "nature and community" mentioned above. Drawing from nature can promote engagement with students' local ecology through critical inquiry and thereby connect scientific research with art making.

The art-science convergence through drawing practice is exemplified by the "Draw the Shape of the Bay" exhibit at the Exploratorium's Observatory. The concept of "Draw the Shape of the Bay" was initially conceived by Susan Schwartzenberg and developed in collaboration with her in-house team of exhibit designers. Susan's aim was to create a public activity that raised awareness of the Bay's role as a major watershed, and to foster an understanding of how the various 
bodies of water that constitute the Bay estuary connect to the urban environment. The exhibit itself was built by Picassa Studio in nearby Oakland, who frequently partner with the Exploratorium in the construction of exhibits (Personal communication, August 24, 2021). Situated next to the Observatory's expansive panorama window, the exhibit invites visitors to pick up a postcard-sized piece of drawing paper and a pencil, and to create a drawing of the San Francisco Bay. This drawing exercise is not a request to produce a perfectly rendered vista of the Bay, rather it is designed to help visitors think about how their life experiences shape their understanding of the Bay. The creative prompt on the exhibit's panel reads:

How do you know the Bay? Most of us have probably seen a map of the Bay Area, but we all have different memories and mental images of this place. Your ideas about the Bay, and its shape, are influenced by where you're from, and by your experiences, including time spent reading maps or looking at the Bay from airplanes.

This drawing exercise creates an opportunity for museum visitors to examine the cultural and societal implications connected to place, nature, and wilderness, aspects that are integral to Graham's (2007) framework of place-based education and eco-art mentioned earlier. The "Draw the Bay" exercise requires both observational drawing (drawing from life) and conceptual drawing (drawing from imagination). The visual thinking elicited by this exhibit balances observation and analysis of the natural world with a critical examination of the urban and personal context of place.

Using the strategy of creating a critical perspective through drawing practice is also employed by Margaret Race. When Margaret visits schools she uses two drawing exercises that help to expose students' preconceived ideas about science. One she calls "Draw a Scientist," the other is "Draw an Alien." In both cases, the drawings expose preconceived stereotypes: the scientist is typically portrayed as a man in a white lab coat, the alien is depicted as a green humanoid with huge eyes and antennae. After Margaret presents her lecture, she asks the students to repeat the drawing exercise, and consequently the drawings become more varied and complex. The scientist may now be a woman, wear ordinary clothes, and be in a natural setting such as a landscape; the alien may be a microbe or a plant. Margaret uses drawing to externalize thoughts, and by making them visible they can become a point of critical discussion that helps students expose their own biases.

Both process-driven and observational drawing can be considered as forms of non-verbal research, a practice that that stretches back to the 16th century with the artist and scientific investigator Leonardo da Vinci (Anderson, 2017). Drawing practice is a compelling convergence point of art and science and should be integrated in non-art curricula as part of graphic facilitation and visual communication (Fava, 2020). Sketching, doodling, tracing, and careful documentation are practices that cross disciplinary boundaries; it is a practice that is intrinsically transdisciplinary.

\section{Conclusion}

The convergence points of the research practice in the domains of art and science illustrate that their methods of inquiry are not disparate, immutable categories, but that they overlap and share similar starting points and aims. The four convergence points of research practice outlined in this study (questioning and interdisciplinarity, nature and community, aesthetics and functionality, drawing and observing) can serve as sources of inspiration for cross-curricular education. Research-based study projects can create opportunities for collaborations between faculties, making both art and science more accessible to those who do not self-identify as "scientists" or "artists." This approach may be of special interest to educational researchers 
working in the field of STEAM education. By disregarding disciplinary subjects and focusing on research practice, educational institutions have the opportunity to exploit art-science convergence points and create a common ground which is accessible to both girls and boys.

\section{Note}

This article draws on research supported by the Social Sciences and Humanities Research Council. The research was undertaken in 2017 in association with Concordia University, Canada. At the time of this study, I was not associated with the Exploratorium or the SETI Institute.

\section{References}

About Us (n.d.). Exploratorium. https://www.exploratorium.edu/about-us

Anderson, G. (2017). Drawing as a way of knowing in art and science. Intellect.

Anderson, T. \& Guyas, A. S. (2012). Earth Education, Interring, and Deep Ecology. Studies in Art Education, 53(3), 223-245. https://doi.org/10.1080/00393541.2012.11518865

Bautista, A., Tan, L. S., Letchmi, D. P. \& Yau, X. (2016). Curriculum integration in arts education: connecting multiple art forms through the idea of 'space.' Journal of Curriculum Studies, 48(5), 610-629. http://dx.doi.org/10.1080/00220272.2015.1089940

Blickenstaff, J. C. (2005), Women and science careers: Leaky pipeline or gender filter? Gender and Education, 17 (4), 369-386. https://doi.org/10.1080/09540250500145072

Brotman, J. S. \& Moore, F. M. (2008). Girls and science: A review of four themes in the science education literature. Journal of Research in Science Teaching, 45(9), 971-1002. https://doiorg.lib-ezproxy.concordia.ca/10.1002/tea.20241

Carl Sagan Center for Research (n.d.). SETI Institute. https://www.seti.org/csc

Charmaz, K. (2006). Constructing grounded theory: A practical guide through qualitative analysis. Sage.

Cheryan, S., Ziegler, S. A., Montoya, A. K., \& Jiang, L. (2016). Why are some STEM fields more gender balanced than others? Psychological Bulletin, 143(1), 1-35. https://doi.org/10.1037/bu10000052

Clapp, E. P. \& Jimenez, R. L. (2016). Implementing STEAM in Maker-Centered Learning. Psychology of Aesthetics, Creativity, and the Arts, 10(4), 481-491. https://doi-org.libezproxy.concordia.ca/10.1037/aca0000066 
Cole, K. C. (2009). Something incredibly wonderful happens: Frank Oppenheimer and the world he made up. Houghton Mifflin Harcourt.

Constantino, T. E. (2002). Problem-based learning: A concrete approach to teaching aesthetics. Studies in Art Education, 43(3), 219-231. https://doi.org/10.2307/1321086

Duncum, P. (2007). Nine Reasons for the continuing use of an aesthetic discourse in art education. Art Education, 60(2), 46-51.

https://www.tandfonline.com/doi/abs/10.1080/00043125.2007.11651636

Fava, M. (2020). A decline in drawing ability? International Journal of Art \& Design Education, 39(2), 319-332. https://doi.org/10.1111/jade.12255

Francis, B., Archer, L., Moote, J., DeWitt, J. \& Yeomans, L. (2017). Femininity, science, and the denigration of the girly girl, British Journal of Sociology of Education, 38(8), 1097-1110. https://doi.org/10.1080/01425692.2016.1253455

Frank, K. (2019). A gender analysis of the occupational pathways of STEM graduates in Canada. Analytical studies branch research paper series. Ottawa: Statistics Canada. https://www150.statcan.gc.ca/n1/pub/11f0019m/11f0019m2019017-eng.pdf

Gettings, M. (2016). Putting it all together: STEAM, PBL, scientific method, and the studio habits of mind. Art Education, 69(4), 10-11. https://doi.org/10.1080/00043125.2016.1176472

Graham, M. A. (2007). Art, ecology and art education: Locating art education in a critical placebased pedagogy. Studies in Art Education, 48(4), 375-391.

https://doi.org/10.1080/00043125.2016.1176472

Greene, M. (1986). The spaces of aesthetic education. The Journal of Aesthetic Education, 20(4), 56-62. https://doi.org/10.2307/3332600

Gude, O. (2008). Aesthetics making meaning. Studies in Art Education, 50(1), 98-103. https://doi.org/10.2307/25475889

Holmes, K., Gore, J., Smith, M. \& Lloyd, A. (2018). An integrated analysis of students' aspirations for STEM careers: Which student and school factors are most predictive? International Journal of Science and Math Education, 16, 655-675. https://doi.org/10.1007/s10763-016-9793-z

Jansen, T. (2016). Strandbeest: Dream machines of Theo Jansen [temporary exhibition]. Exploratorium, San Francisco, California, USA.

Jacobs, G. (2011, June 27). Scientist interview - Margaret Race - planetary protector. SETI Institute. https://www.seti.org/scientist-interview-margaret-race-planetary-protector 
Jill Tarter - Beating the odds (n.d.) SETI Institute. https://www.seti.org/seti-

institute/project/details/jill-tarter--beating-odds

Jabobs, C. E., Kuriloff, P. J., Andrus, S. H. \& Cox, A. B. (2014). Reaching girls. Phi Delta Kappan, 96(1), 68-75. http://pdk.sagepub.com/content/96/1/68

Kessels, U. (2014). Bridging the gap by enhancing the fit: How stereotypes about STEM clash with stereotypes about girls. International Journal of Gender, Science and Technology, 7(2) 280296. http://genderandset.open.ac.uk/index.php/genderandset/article/viewFile/392/687

Kessels, U., Heyder, A., Latsch, M. \& Hannover, B. (2014). How gender differences in academic engagement relate to students' gender identity, Educational Research, 56 (2), 220-229.

https://doi.org/10.1080/00131881.2014.898916

Kuriloff, P., Andrus, S. \& Jacobs, C. (2017). Teaching girls: How teachers and parents can reach their brains and hearts. Rowman \&

Littlefield. https://doi.org/10.1080/00131881.2014.898916

Land, M. (2013). Full STEAM ahead: The benefits of integrating the arts into STEM. Procedia Computer Science, 30, 547-552. https://doi.org/10.1016/j.procs.2013.09.317

Leaper, C., \& Spears Brown, C. (2008). Perceived experiences with sexism among adolescent girls, Child Development, 79(3), 685-704. https://doi.org/10.1111/j.1467-8624.2008.01151.x

Lupart, J. L., Cannon, E. \& Telfer, J.A. (2004). Gender differences in adolescent academic achievement, interests, values and life-role expectations. High Ability Studies, 15(1), 25-42. https://doi.org/10.1080/1359813042000225320

Madden, M. E., Baxter, M., Beauchamp, H., Bouchard, K., Habermas, D., Huff, M., Ladd, B., Pearon J. \& Plague, G. (2013). Rethinking STEM education: An interdisciplinary STEAM curriculum. Procedia Computer Science, 20, 541-546.

https://doi.org/10.1016/j.procs.2013.09.316

Maeda, J., Joichi, I. (2015). Q\&A. Design Management Review, 26(1), 10-14.

Matyas, M.L. \& Dix, L.S. (Eds.). (1992). Science and engineering programs: On target for women? National Academy Press.

Marshall, J. (2014). Transdisciplinarity and art integration: Toward a new understanding of artbased learning across the curriculum. Studies in Art Education, 55(2), 104-127.

https://www.jstor.org/stable/24465489

May, S. \& Clapp, E. P. (2017). Considering the role of the arts and aesthetics within makercentred learning. Studies in Art Education, 58(4), 335-350.

https://doi.org/10.1080/00393541.2017.1368287 
Meece, J. L., Bower Glienke, B. \& Burg, S. (2006). Gender and motivation. Journal of School Psychology, 44(5), 351-373. http://dx.doi.org/10.1016/j.jsp.2006.04.004

Merriam, S. B. (2002). Qualitative research in practice: Examples for discussion and analysis. Jossey-Bass.

Müller, J., Polansky, D., Novak, P., Foltin, C. \& Polivaev, D. (2014). Freemind (Version 1.0.1) [Computer software]. http://freemind.sourceforge.net/wiki/index.php/Main_Page

National Research Council, Committee on Women in Science and Engineering (NRC). (1991). Women in science and engineering: Increasing their numbers in the 1990s. National Academy Press. https://doi.org/10.17226/1878

National Science Foundation (NSF), National Center for Science and Engineering Statistics (2019). Women, Minorities, and Persons with Disabilities in Science and Engineering:

2019. Special Report NSF 19-304. https://www.nsf.gov/statistics/wmpd.

Natural Sciences and Engineering Research Council Canada (NSERC) (2017). Women in science and engineering in Canada. NSERC. https:/www.nserc-crsng.gc.ca/_doc/ReportsRapports/WISE2017_e.pdf

Nicole Catrett (n.d.). Exploratorium. https://www.exploratorium.edu/tinkering/tinkerers/nicolecatrett

Organisation for Economic Co-operation and Development (OECD) (2018). PISA 2015 Results in focus. OECD Publishing. https://www.oecd.org/pisa/pisa-2015-results-in-focus.pdf

Owen, C. (2020). Through a glass darkly: The teaching and assessment of drawing skills in the UK post-16 art \& design curriculum. International Journal of Art \& Design Education, 39(2), 333-345. https://doi.org/10.1111/jade.12265

Pell, A. N. (1996). Fixing the leaky pipeline: Women scientists in academia. Journal of Animal Science, 74(11), 2843-2848. https://doi.org/10.2527/1996.74112843x

Peppler, K. \& Wohlwend, K. (2018). Theorizing the nexus of STEAM practice. Arts Education Policy Review, 119(2), 88-99. https://doi.org/10.1080/10632913.2017.1316331

Race, M. S. (1995). Societal issues as mars mission impediments: planetary protection and contamination concerns. Advances in Space Research: The Official Journal of the Committee on Space Research (Cospar), 15(3), 285-92. https://doi.org/10.1016/S0273-1177(99)80099-4

Root-Bernstein, R., Pathak, A. \& Root-Bernstein, M. (2019a). A review of ACD-STEMM integration: Part 1: A taxonomy of integrated bridges. Leonardo, 52(5), 492-493.

https://doi.org/10.1162/leon_a_01579

Root-Bernstein, R., Pathak, A. \& Root-Bernstein, M. (2019b). A review of ACD-STEMM integration: Part 3: Controlled studies of additional transdisciplinary bridges for

Canadian Review of Art Education, 48(1)

Fall 2021 
arts-science pedagogy and general conclusions. Leonardo, 52(5), 496-497.

https://doi.org/10.1162/leon_a_01581

Sagan, C. (1985). Contact. Simon and Schuster.

Saldaña, J, (2009). The coding manual for qualitative researchers. SAGE Publications.

Scoles, S. (2017). Making contact: Jill Tarter and the search for extraterrestrial intelligence. Pegasus Books.

Søberg, S. \& Schreiner, C. (2019). ROSE (The Relevance of Science Education). The development, key findings and impacts of an international low cost comparative project. Final Report, Part 1 (of 2). Oslo University.

SETI Institute Artists in Residence (AIR) Program (n.d.). SETI Institute. https://www.seti.org/air

Steele, J. R. \& Ambady, N. (2006). “Math is hard!” The effect of gender priming on women's attitudes. Journal of Experimental Psychology, 42, 428-436.

https://doi.org/10.1016/j.jesp.2005.06.003

Susan Schwartzenberg (n.d.). Exploratorium. https://www.exploratorium.edu/about/staffartists/susan-schwartzenberg

Tan, E., Calabrese Barton, A., Kange, H. \& O’Neill, T. (2013). Desiring a career in STEM-related fields: How middle school girls articulate and negotiate identities-inpractice in science. Journal of Research in Science Teaching, 50(10), 1143-1179. https://doi.org/10.1002/tea.21123

Tavin, K. (2007). Eyes wide shut: The use and uselessness of the discourse of aesthetics in art education. Art Education, 60(2), 40-45. https://doi.org/10.1080/00043125.2007.11651635

Tavin, K. (2008). The magical quality of aesthetics: Art education's Object a (and the new math). Studies in Art Education, 49(3), 268-271. https://www.jstor.org/stable/24467885

Walton \& O. R. Young (Eds.), Science diplomacy: Antarctica, science and the governance of international spaces 143-153. Smithsonian Institution Scholarly Press.

Vincent-Ruz, P. \& Schunn, C. D. (2017). The increasingly important role of science competency beliefs for science learning in girls. Journal of Research in Science Teaching, 54(6), 790-822. https://doi.org/10.1002/tea.21387

Vincent-Ruz, P. \& Schunn, C. D. (2018). The nature of science identity and its role as the driver of student choices. International Journal of STEM Education, 5(48), https://doi.org/10.1186/s40594-018-0140-5. 
Wang, M.T. \& Degol, J. L. (2017). Gender gap in science, technology, engineering and mathematics (STEM): Current knowledge, implications for practice, policy, future directions, Educational Psychology Review, 29(119), 119-140. https://doi.org/10.1007/s10648-015-9355-x

Wolfe, M. J. (2019). Smart girls traversing assemblages of gender and class in Australian secondary mathematics classrooms. Gender and Education, 31(2), 205-221.

https://doi.org/10.1080/09540253.2017.1302078

Wolff, J. (2013 - ongoing). Bay Lexicon [permanent museum exhibit]. Exploratorium, Fisher Bay Observatory Gallery 6: Observing Landscapes, San Francisco, California, USA.

Wynn, T., \& Harris, J. (2012). Towards a STEM + Arts Curriculum: Creating the teacher team. Art Education, 65(5), 42-47. https://doi.org/10.1080/00043125.2012.11519191

Yin, R. K. (2009). Case study research: Design and methods. Sage. 